THE ANNALS OF "DUNĂREA DE JOS" UNIVERSITY OF GALATI

FASCICLE III, 2019, VOL. 42, NO.2, ISSN 2344-4738, ISSN-L 1221-454X

ELECTROTECHNICS, ELECTRONICS, AUTOMATIC CONTROL, INFORMATICS

Article DOI: $\underline{\text { https://doi.org/10.35219/eeaci.2019.2.02 }}$

\title{
L, LC AND LCL FILTER CHOOSING BY C-TOOL APPLICATION
}

\author{
Ciprian Daniel Bălănuță ${ }^{1}$, Gelu Gurguiatu' ${ }^{1}$, Alexandru Dușa ${ }^{1}$, Emil Mina Roșu ${ }^{1}$, \\ Ion Voncilă ${ }^{1}$, Constantin Drogeanu ${ }^{2}$ \\ ${ }^{1}$ The University ,,Dunărea de Jos” of Galați \\ ${ }^{2} U N I E L-S E R V$
}

\begin{abstract}
Energy efficiency is crucial for sustainable development. Among the aspects related to energy efficiency in electricity, the power quality is a key topic. Active power filters (APF) are an efficient solution to improve the power quality. Designing APF requires solid knowledge about the means to evaluate the power quality and about the equipment available on the market. This paper presents a software application, called "C-tool", which is capable to indicate the right elements available for the construction of the L, LC and LCL filters, included in the structure of APFs. This application was developed in the context of the project: „Knowledge Transfer Regarding the Energy Efficiency Increase and Intelligent Power Systems" (acronym CRESC-INTEL). This paper belongs to a series of articles aiming to present the C-tool application to the scientific community.
\end{abstract}

Keywords: Energy efficiency, Power quality, active power filter, L filter, LC filter, LCL filter, electronic application.

\section{INTRODUCTION}

The rapid technological development of the past decade greatly diversified the types of loads, amount of power, quality requirements for the energy providers. Most of the loads are nonlinear, producing important harmonic and reactive components, as well as imbalances in three-phase systems. Examples of such situations are very common: adjustable electric drives, electric furnaces, energy transport in DC, conversion of unconventional energies, supply systems for computer networks, unbalanced threephase systems with zero charging, and so on. The effects of nonlinear loads propagate in the entire grid: production, transport, and final conversion to the receiver. Negative effects are important: reducing capacity to produce active power useful in station; decreasing energy transmission efficiency; reducing the efficiency of the system or even making it unavailable.
The solution to overcome these problems is to use appropriate active power filters next to the load. There are two main types of active power filters: shunt active power filters and series active power filters. Usually the shunt active power filter is connected into common coupling point (PCC) through a passive filter, which can be an inductance. There are studies proving that a better solution to connect APF in PCC is with passive filter realized with inductances, resistances and capacity (Rajasekharareddy et al. 2018; Ben Habib et al, 2003, Dey \& Mekhilef, 2015). 
However, the active power filter is requiring special conditions to be connected in common coupling point (PCC). Among the solutions to this problem proposed in the literature, we cite: (Moran et al, 1995; Hojabri, 2015, and Bina \& Pashajavid, 2009).

In this, three types of passive filters: L, LC and LCL filters are considered, each of them with their own characteristics and mathematical model.

The important and rapid progress in the power semiconductor field, capable of taking on increasing voltages and currents, allow for the development of hard converters to provide the harmonic and reactive components required for nonlinear loads. On the other hand, the control techniques of the converters have allowed the development of new control systems which consider the continuous character of the compensation and the dynamic performance, systems called active power filters, APF. In the same time there are used also other systems: APLC Active power line conditioner; IRPC - Instantaneous reactive power compensator; CAPQ - Conditioner of active power quality (Agaci et al, 2007). Thus, a second way of solving the problem has developed, a more advanced, but more complex and obviously more expensive one.

In the spirit of this path we proposed the project: "Knowledge transfer regarding the energy efficiency increase and intelligent power systems", (acronym CRESC-INTEL), where the study described in this article belongs. The general objective of the project is to improve the transfer of technological knowledge and skilled personnel between the "Dunarea de Jos" University in Galati, and SMEs that develop electricity business with specific market outcomes. The project aims at establishing partnerships between the "Dunarea de Jos" University in Galati and enterprises interested in acquiring knowledge, including abilities and competencies to increase energy efficiency and intelligent power systems in order to obtain a competitive solution, for an intelligent Active Power Filter (APF).

\section{PASSIVE FILTER TO CONNECT APF IN PCC}

In order to achieve the best results in realizing a passive filter to connect the active power filter in common coupling point one must follow the next steps:

a. Perturbations identification and their producer. According to (SIER, 2019), it is necessary to know the non-linear load and of course the harmonic spectrum of the current.

b. Determining the severity of the various disturbances and the limits accepted at different points (nodes) of the grid. In principle, the negative effects on the grid caused by the harmonic disturbances must be well known.

c. Analyze the consequences on the distribution network and users. The negative phenomena mentioned above will lead to a drastic decrease of the reliability of the grid and additional energy consumption on each harmonic.

d. Choosing the specific active filter topology to reduce identified disturbances in the nonlinear consumer power supply grid (serial filter, parallel filter, hybrid filter, UPQC combined filters).

e. Selection / dimensioning of grid connection systems - in PCC - the specific active filter topology chosen (passive filters - usually low pass filters (FTJ)) - adapters/smoothing coils, damping resistors, separating transformers, etc. ).

f. Testing - by simulation - of the efficiency of the solution found/chosen to reduce the disturbances initially identified in the particular area of the considered power supply grid.

In developing of the C-tool it was considered the $\mathrm{L}$, LC and LCL passive connection filter presented in the following paragraph.

\section{L FILTER}

The first type of passive coupling filter considered in C-tool application is $\mathrm{L}$ filter. To calculate the elements of the $\mathrm{L}$ filter it was used the method presented in [MOR 95]. This method is based on the requirement that, for a given frequency, the slope of the current through the active power filter is less than that of the triangular carrier signal defining the switching frequency. The slope of the carrier signal is defined by:

$$
\chi=4 \cdot \varepsilon \cdot f_{s}
$$

where:

$\varepsilon$ represents the amplitude of the triangular signal,

$f_{s}$ switching frequency.

The maximum current $i_{F A}$ slope for the active filter with a median point is given by:

$$
\frac{d i_{F A}}{d t}=\frac{0.5 \cdot U_{c c}+U_{s m}}{L_{F A}}
$$

from where:

$$
L_{F A}=\frac{0.5 \cdot U_{c c}+U_{s m}}{4 \cdot \varepsilon \cdot f_{s}}
$$




\section{LCL FILTER}

where:

$U_{c c}$ - the voltage in the DC bar,

$U_{s m}$ - maximum supply voltage.

The connection of the $\mathrm{L}$ filter is presented in Fig. 1

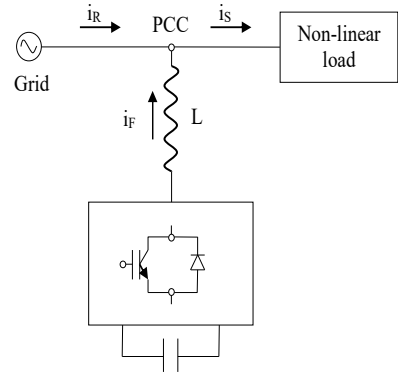

Fig. 1 L filter

\section{LC FILTER}

To calculate the value of the $\mathrm{LC}$ filter in the C-tool application it was considered the following:

$$
\begin{gathered}
L_{F A}=\frac{0.5 \cdot U_{c c}+U_{s m}}{4 \cdot \varepsilon \cdot f_{s}} \\
C=\frac{1}{\left(2 \pi f_{C}\right)^{2} L}
\end{gathered}
$$

The second type of passive coupling filter considered in C-tool application is LC filter. The connection of the LC filter is presented in Fig. 2

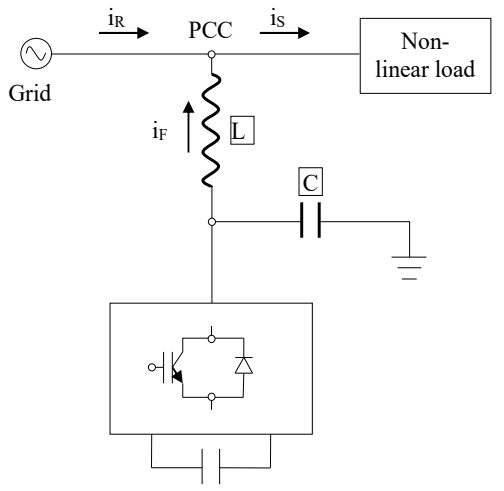

Fig. 2 LC filter
The 3th type of passive coupling filter considered in $\mathrm{C}$-tool application is LCL filter. The elements are dimensioned using the following equations:

$$
\begin{gathered}
L_{F A}=\frac{0.5 \cdot U_{c c}+U_{s m}}{4 \cdot \varepsilon \cdot f_{s}} \\
L_{1}=(4 \sim 6) L_{2} \\
C=\frac{1}{\left(2 \pi f_{C}\right)^{2} L} \\
R_{d}=3 \times \frac{1}{2 \pi f_{r e f} C}
\end{gathered}
$$

The connection of the LCL filter is presented in Fig.3.

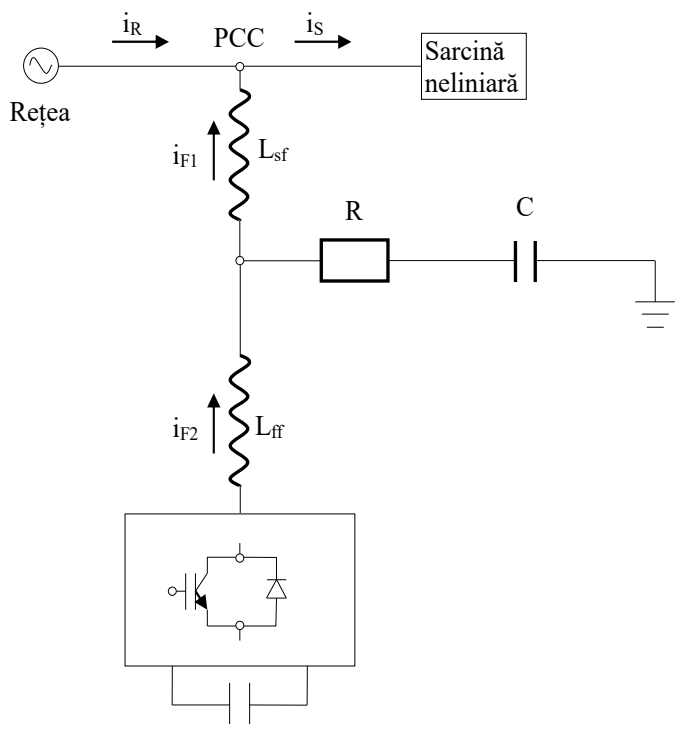

Fig. 3 LCL filter

Considering that the highest rank of the compensated harmonics is 40 , applying a factor of 1.25 to $f_{\text {cmax }}$ results in a lower limit of $2.5 \mathrm{kHz}$ and an upper limit of $3 \mathrm{kHz} \quad\left(0.5 \mathrm{xf}_{\min }=3 \mathrm{kHz}\right)$ for the resonance frequency.

\section{C-TOOL APPLICATION}

Following the above equations we developed the Ctool application structured on 6 main tabs:
C-tool
$\checkmark$ Filtru LC
$\checkmark$ Filtru LCL

$\checkmark$ BD L

$\checkmark$ BD C

$\checkmark$ Filtru L 
The $\mathrm{C}$-tool is the input tab for the parameters required for sizing the passive connection filter of the active power filter as well as the tab on which the values of the required elements can be read.

Within the field "Input data about the load" data on electrical load are requested. Thus, the user must introduce the following electrical characteristics of the load:

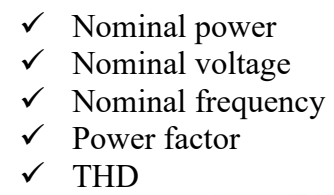

\begin{tabular}{|c|c|c|c|}
\hline \multicolumn{4}{|c|}{ Input data about the load } \\
\hline Type of parameter & Indice & Valori & UM \\
\hline Nominal power & 5 & 50 & KVA \\
\hline Nominal voltage & U & 400 & v \\
\hline Nominal frequency & $f$ & 50 & $\mathrm{~Hz}$ \\
\hline Power factor & $k_{p}$ & 0.9 & \\
\hline THD & $k_{0}$ & 25 & $\%$ \\
\hline
\end{tabular}

Fig. 4 Input data about the load

Within the field "RMS value of currents in the electrical system" data on electric currents is requested. The user must then enter the following values of the currents:

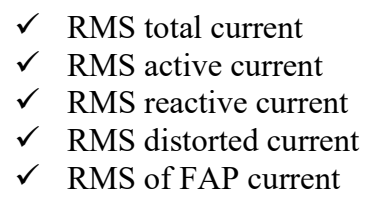

\begin{tabular}{|l|c|c|c|}
\hline \multicolumn{5}{|c|}{ RMS value of currents in the electrical system } \\
\hline RMS total current & $\mathrm{I}_{\text {total }}$ & 65.0 & $\mathrm{~A}$ \\
\hline RMS active current & $\mathrm{I}_{\text {p }}$ & 56.6 & $\mathrm{~A}$ \\
\hline RMS reactive current & $\mathrm{I}_{10}$ & 27.4 & $\mathrm{~A}$ \\
\hline RMS distorted current & $\mathrm{I}_{\mathrm{D}}$ & 16.2 & $\mathrm{~A}$ \\
\hline RMS of FAP current & $\mathrm{I}_{\text {f }}$ & 31.9 & $\mathrm{~A}$ \\
\hline
\end{tabular}

Fig. 5 RMS value of currents in the electrical systems

Within the field "FAP data" data is requested about the active power filter. Thus, the user must enter the following values:

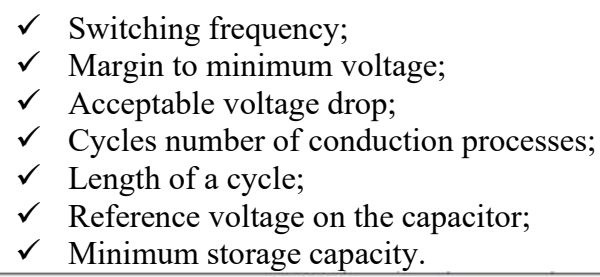

\begin{tabular}{|l|c|c|c|}
\hline \multicolumn{3}{|c|}{ FAP data } \\
\hline Switching frequency & $\mathrm{f}_{\mathrm{sw}}$ & 15 & $\mathrm{kHz}$ \\
\hline Margin to minimum voltage & $\Delta \mathrm{U}_{\mathrm{cmin}}$ & 10 & $\%$ \\
\hline Acceptable voltage drop & $\Delta \mathrm{U}_{\mathrm{C}}$ & 5 & $\%$ \\
\hline Cycles number of conduction processes & $\mathrm{n}_{\mathrm{c}}$ & 38.11 & $\mathrm{~V}$ \\
\hline Length of a cycle & $\mathrm{t}_{\mathrm{c}}$ & 0.0033 & $\mathrm{~s}$ \\
\hline Reference voltage on the capacitor & $\mathrm{U}_{\mathrm{C}}$ & 762.10 & $\mathrm{~V}$ \\
\hline \multicolumn{2}{|l|}{} \\
\hline Minimum storage capacity & $\mathrm{C}_{\min }$ & 2.53 & $\mathrm{mF}$ \\
\hline Passive filters type & \multicolumn{2}{|l}{} \\
\hline
\end{tabular}

Fig. 6 FAP data
Within the field "Passive connection filter" data on the passive filter that can be used is provided. There are three types of filters: L, L-C, L-C-L. Thus, the user can choose from the three available type of passive filters the one which is the best. For each of them, C-tool provides the following information:

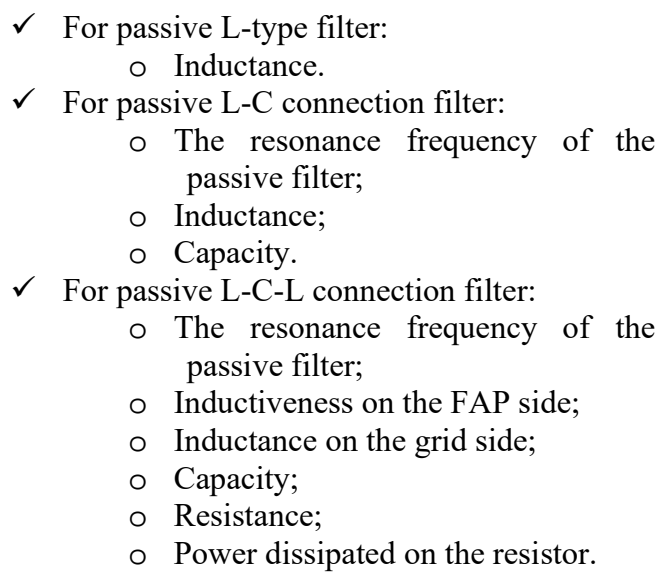

$\checkmark$ For passive L-C-L connection filter:

o The resonance frequency of the passive filter;

0 Inductiveness on the FAP side;

o Inductance on the grid side;

o Capacity;

o Resistance;

o Power dissipated on the resistor.

\begin{tabular}{|c|c|c|c|}
\hline \multicolumn{4}{|l|}{$\mathrm{L}$} \\
\hline Inductance & Lf & 1.23 & $\mathrm{mH}$ \\
\hline \multicolumn{4}{|l|}{ L.C } \\
\hline The resonance frequency of the passive filter & fc & 2500.00 & $\mathrm{~Hz}$ \\
\hline Inductance & Lf & 1.23 & $\mathrm{mH}$ \\
\hline Capacity & Cf & 3.28 & uF \\
\hline \multicolumn{4}{|c|}{ L-C.L } \\
\hline The resonance frequency of the passive filter & fc & 2500.00 & $\mathrm{~Hz}$ \\
\hline Inductiveness on the FAP side & Lff & 0.99 & $\mathrm{mH}$ \\
\hline Inductance on the grid side & Lsf & 0.25 & $\mathrm{mH}$ \\
\hline Capacity & c & 4.11 & uf \\
\hline Resistance & $\mathbf{R}$ & 46.52 & $\Omega$ \\
\hline Power dissipated on the resistor & Pr & 1146.53 & w \\
\hline
\end{tabular}

Fig. 7 Connection passive filter elements

Also, for the three types of filters, there are diagrams presented on a specified page.

As an example for the passive connection filter there are presented the three types of filters with their elements and with their diagrams. 
THE ANNALS OF "DUNĂREA DE JOS" UNIVERSITY OF GALATI

FASCICLE III, 2019, VOL. 42, NO. 2, ISSN 2344-4738, ISSN-L 1221-454X

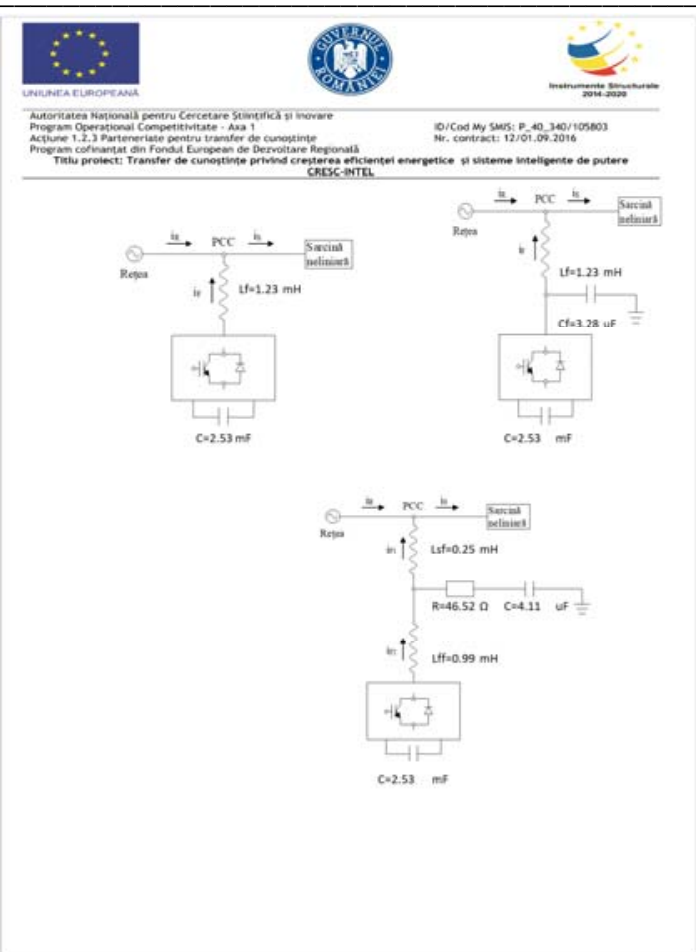

Fig. 8 The details about the L, LC, LCL filter

\section{CONCLUSIONS}

The C-tool application was developed following the mathematical model presented in the literature.

The C-tool is a useful application for the users who want to build their own active power filter. Starting from data about the load, currents and active power filter the application can provide the characteristics of the connection passive filter. C-tool can calculate three type of passive filter: L, LC, LCL. Also, C-tool is providing the topology of the passive filter indicating the value of each element $(\mathrm{L}, \mathrm{C}, \mathrm{R})$.

\section{REFERENCES}

Rajasekharareddy Chilipi, Naji Al Sayari, Khalifa Al Hosani, Muhammed Fasil, Abul R. Beig - Third order sinusoidal integrator (TOSSI)-based control algorithm for shunt active power filter under distorted and unbalanced voltage conditions -Electrical Power and Energy Systems 96 (2018), pp. 152-162;

M.C. Ben Habib, E. Jacquot, S. Saadate - An Advanced Control Approach for a Shunt Active Power Filter - RE\&PQJ, Vol. 1, No.1, April 2003, pp. 569-573, https://doi.org/10.24084/repqj01.429;
Papan Dey, Saad Mekhilef - Current Controllers of Active Power Filter for Power Quality Improvement: A Technical Analysis AUTOMATIKA 56 (2015) 1, pp. 42-54;

L. A. Morán, J. Dixon, \& R. R. Wallace, “A threephase active power filter operating with fixed switching frequency for reactive power and current harmonic compensation", IEEE Trans. Ind. Electron., vol. 42, No. 4, pp. 402-408, August 1995.

Mojgan Hojabri, Mehrdad Hojabri, Design, application and comparison of passive filters for three-phase grid-connected renewable energy systems, ARPN Journal of Engineering and Applied Sciences, VOL. 10, NO. 22, DECEMBER, 2015, ISSN 1819-6608

Tavakoli Bina, E. Pashajavid, An efficient procedure to design passive LCL-filters for active power filters, Electric Power Systems Research, 79 (2009) 606-614, ISSN: 0378-7796

Agaci H., Watanabe E.H., Aredes M., Instantaneous Power Theory and Applications Power Conditioning. Villey 2007.

SIER, 2019 http://www.sier.ro/Articolul_3_3_3.pdf, on-line on 17.05.2019 